\title{
Rare Triple Lesional Association in Epileptic Seizure: Fracture of the Coracoid Process - Fracture of the Acromion and Acromioclavicular Dislocation
}

\author{
Ayoub Mjidila*, Youness Dahmani, Ismail kabbaj, M. Boufettal, Reda Allah Bassir, M. O. Lamrani, Kharmaz, MS
} Berrada

Department of Orthopedic Surgery, Ibn Sina Hosipital, Mohamed V University, Faculty of Medicine of Rabat, Rabat, Morocco

DOI: $\underline{10.36347 / \text { sasjs.2021.v07i02.001 }}$

| Received: 08.01.2021 | Accepted: 19.01.2021 | Published: 02.02.2021

*Corresponding author: Ayoub Mjidila

\section{Abstract}

Concomitant fracture of the coracoid process and acromion associated with acromioclavicular dislocation is very rare. Diagnosis is based on clinical features and standard radiology. We report the case of a 26-year-old man with known epilepsy but not compliant with treatment, who presents following a seizure with a concomitant fracture of the coracoid process and the acromion associated with acromioclavicular dislocation of the left shoulder. The patient was treated conservatively, involving strapping of the acromioclavicular joint associated with immobilization of the shoulder elbow at $90^{\circ}$ by a mayo clinic functional results were good.

Keywords: Fracture of the coracoid process-fracture of the acromion, acromio-clavicular dislocation.

Copyright $\odot 2021$ The Author(s): This is an open-access article distributed under the terms of the Creative Commons Attribution 4.0 International License (CC BY-NC 4.0) which permits unrestricted use, distribution, and reproduction in any medium for non-commercial use provided the original author and source are credited.

\section{INTRODUCTION}

Coracoid fracture is an uncommon injury, accounting for only $2 \%$ to $13 \%$ of all scapular fractures and approximately $1 \%$ of all fractures [1-3]. On the other hand, FRACTURE OF THE ACROMION and AC joint dislocation associated with coracoid process (CP) fracture is an extremely rare association of injuries. Current literature contains few numbers of published cases, and available knowledge about this rare injury comes from the published case reports.

The injury mechanism involved in these combined injuries remains controversial and there is no definite consensus on its treatment.

\section{Case Presentation}

This is a 26-year-old man, right-handed, carpenter, known epileptic but not compliant with the prescribed treatment (phenobarnital and sodium valproate).

The mechanism was direct trauma to the left shoulder (fall during seizure) 7 days before admission. The clinical examination found a patient in good general condition, skin abrasion over the acromial end of the clavicle, pain on palpation of the acromioclavicular joint and a slight piano touch.
Limitation of shoulder movements was observed: abduction was limited to $40^{\circ}$ and flexion $60^{\circ}$. Absence of vasculo-nervous involvement.

The standard X-ray of the shoulder shows a fracture of the base of the coracoid process + an undisplaced fracture of the acromion (Fig 1 and 2).

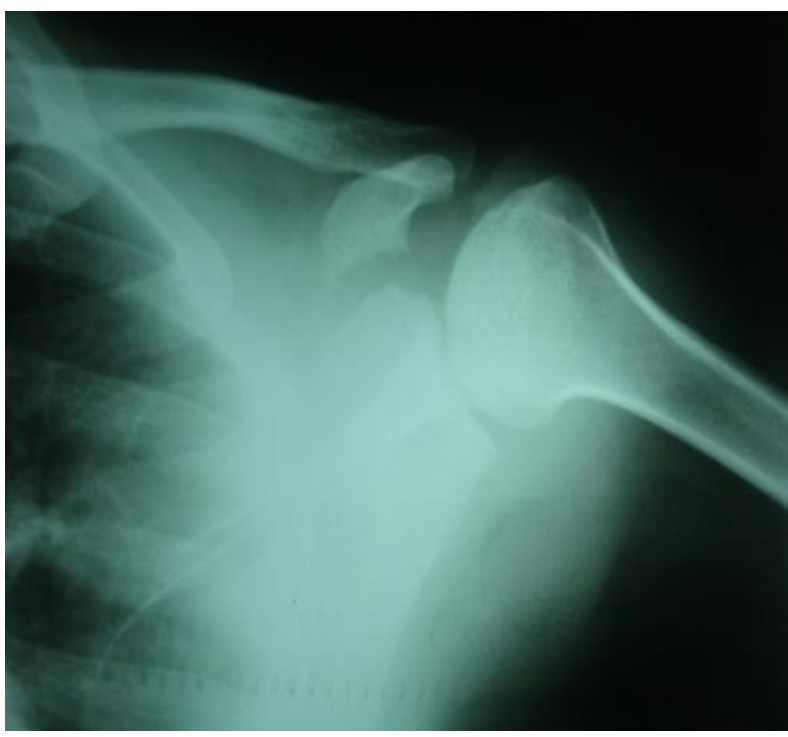

Fig-1: Shoulder $x$-ray showing the fracture of the base of the coracoid process 


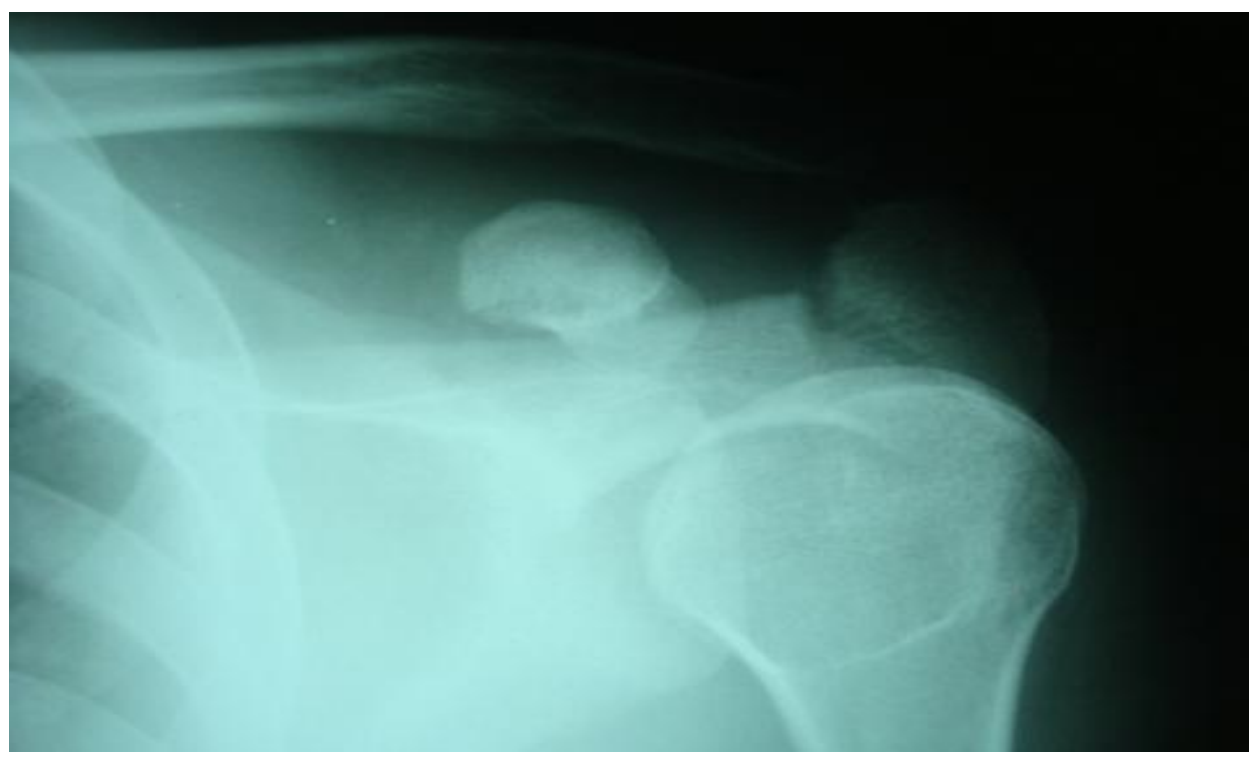

Fig-2: AP shoulder x-ray showing acromion base fracture

A CT scan of the shoulder (Fig-3) with 3D reconstruction (Fig-4) showed a fracture of the base of the coracoid process, a fracture of the base of the acromion as well as a Rockwood type II acromioclavicular disjunction.

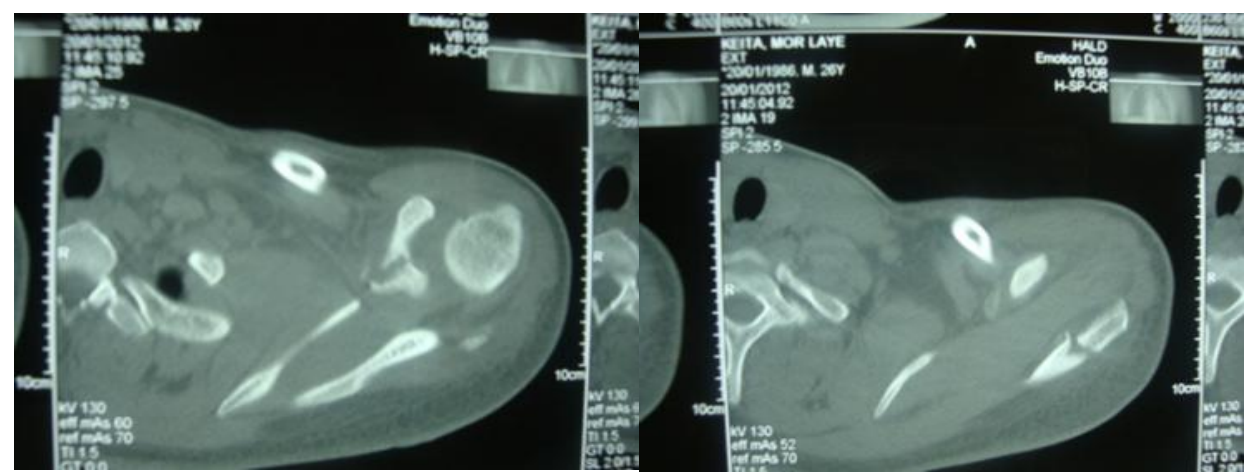

Fig-3: Shoulder CT scan: axial section showing the fracture of the acromion and the coracoid process

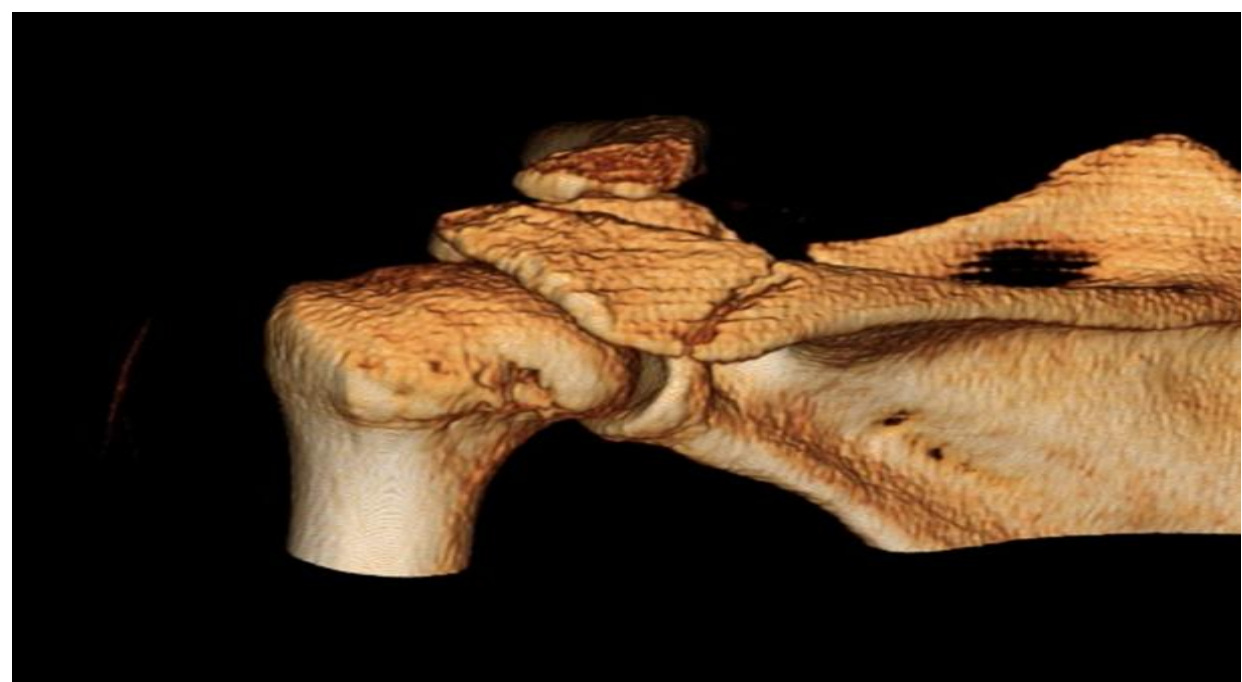

Fig-4: 3D scan of the shoulder

The treatment was conservative, consisting of strapping of the acromioclavicular joint, immobilization of the shoulder at $90^{\circ}$ elbow using a mayo clinic for 3 weeks. Analgesics and anti-inflammatory drugs, with adjustment of the doses of antiepileptic. 
The evolution on D28; functional rehabilitation by pendular movements was started. On
D60 the functional result is satisfactory, with a slight amyotrophy of the shoulder stump to be noted (Fig-5).

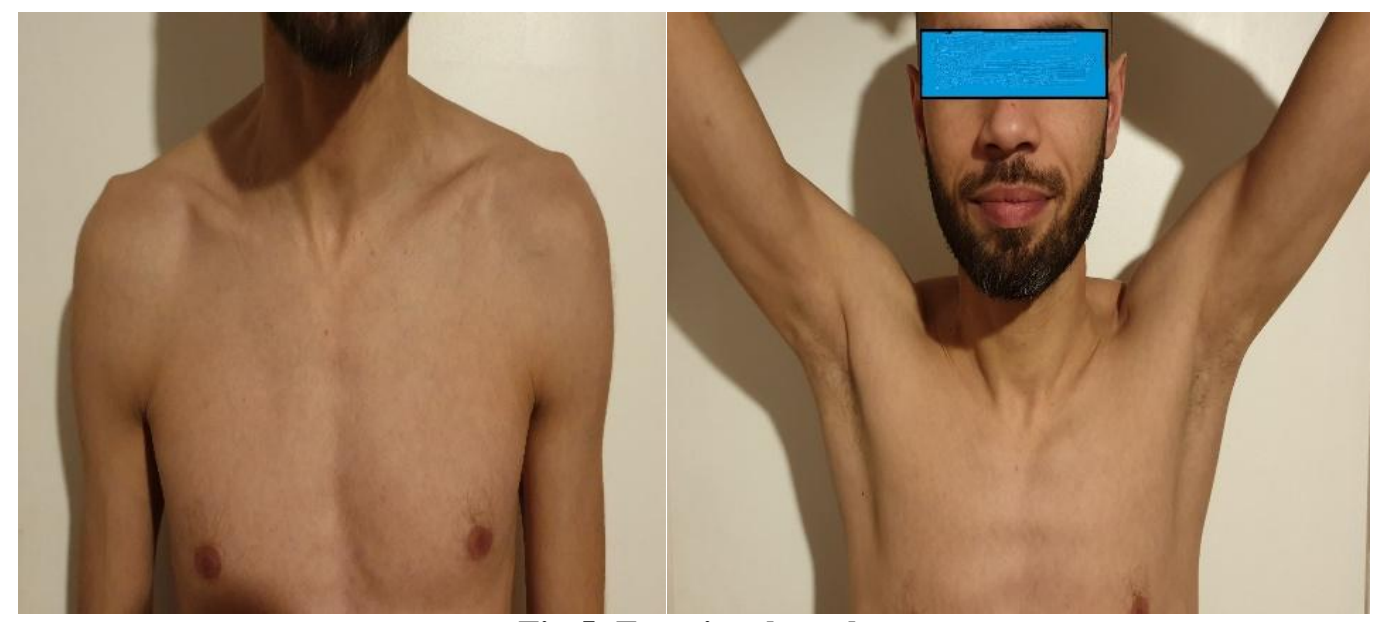

Fig-5: Functional result

\section{DisCUSSION}

The fracture of the coracoid process associated with the dislocation fracture of the acromioclavicular joint is a rare lesion. Urist described for the first time in 1941 the fracture of the coracoid process associated with an acromioclavicular dislocation [4].

The mechanism is either direct leading to a fracture of the coracoid process, or complex and controversial: association of the 3 lesions. It is the result of a succession of events: most often fall on the hand, humeral head impact on the acromion and fracture of the acromion with acromioclavicular distortion [5].

Diagnosing a fracture of the coracoid process with concomitant AC separation and fracture of the acromion can be difficult $[6,7]$.

Although the fracture of the coracoid process is difficult to visualize on routine $\mathrm{x}$-rays due to marked shortening and projection onto the acromion or blade of the scapula.

The precise diagnosis of a fracture of the coracoid process requires special $\mathrm{x}$-rays or a CT scan. Protass described a $30^{\circ}$ to $35^{\circ}$ cephalic radiograph with the patient supine [8]. Computed tomography can better assess the coracoid process and acromion fracture and provide the clinician with more detailed information about the site and extent of the fractures.

Choosing the right treatment for this combined injury can also be difficult. There are a number of different therapeutic methods reported in the literature [9].

Of the 20 series of cases reported in adults in Anglo-Saxon literature, 12 were treated surgically [10$11]$ and eight were treated non-operatively [6, 10, 12]. There is currently no specific therapeutic indication.
Almost half of all reported patients have been treated surgically. Surgical treatment allows direct inspection of the joint injury and the removal of any fracture fragments or other obstacles to reduction. It also allows anatomical reduction and secure fixation, allowing the resumption of shoulder movement sooner than with closed techniques, which is especially important for patients performing heavy work [13].

Almost half of all reported patients have been treated conservatively with a sling, shoulder immobilizer or plastic abduction cast. In some cases managed by conservative therapy, pain [9] and residual acromioclavicular dislocation [14] were observed, but these complications did not jeopardize arm movement. Conservative treatment fails primarily due to the interposition of the articular disc, frayed capsular ligaments, and fragments of articular cartilage between the acromion and the clavicle.

\section{CONCLUSION}

Both surgical and conservative treatment for this combined injury seemed to achieve similar longterm follow- up results. Surgical treatment is recommended particularly under the following circumstances: failed conservative treatment; younger patients or heavy laborer; and patients who particularly desire a good cosmetic result.

\section{Conflict of Interest: None.}

\section{REFERENCES}

1. Ada JR, Miller ME. Scapular fractures: analysis of 113 cases. Clin Orthop. 1991; 269:174-80.

2. Eyres KS, Brooks A, Stanley D. Fractures of the coracoid process. J Bone Joint Surg Br. 1995; $77: 425-8$.

3. Ogawa K, Yoshida A, Takahashi M, Ui M. Fractures of the coracoid process. The Journal of 
bone and joint surgery. British volume. 1997 Jan;79(1):17-9.

4. Urist M. Complete dislocation of the acromioclavicular joint. J Bone Joint Surg Am. 1963; 45:1750

5. Rockwood CA. Injuries to the acromioclavicular joint. In : Rockwood CA, Grenn DP, eds. Fractures in adults, vol 1, 2nd ed. Philadelphia : Lippincott, 1984:860

6. Carr A, Broughton N. Acromioclavicular dislocation associated with a fracture of the coracoid process. J Trauma. 1989; 29: 125-6.

7. Combalia A, Arandes J, Alemany X, Ramon R. Acromioclavicular dislocation with epiphyseal separation for the coracoid process: report of a case report and review of the literature. J Trauma. 1995; 38: 812-5.

8. Protass J, Stampfli F, Osmer J. Diagnosis of fracture of the coracoid process in acromioclavicular separation. Radiology. 1975; 116: 61-4.

9. Kim K, Rhee K, Shin H, Kim D, Shin H. Displaced fracture of the coracoid process associated with acromioclavicular dislocation: a two-bird-one-stone solution. J Trauma. 2009; 67: 403-5.

10. Montgomery S, Lloyd R. Avulsion fracture of the coracoid epiphysis with acromioclavicular separation. J Bone Joint Surg. 1977;3 0:1597-9.

11. Eyres K, Brooks A, Stanley D. Fractures of the coracoid process. J Bone Joint Surg Br. 1995; 77:425-8.

12. Bernard T, Brunet M. Fractured coracoid process in acromioclavicular dislocations. Report of four cases and review of the literature. Clin Orthop Relat Res. 1983; 175:227-32.

13. Jeffrey AD, John RC. Dislocations aiguës Dans: Canale ST, Beaty JH, eds. Campbell's Operative Orthopaedics, 11e éd. Xi'an: World Publishing Company, 2007; 3587-3592.

14. Bernard TN Jr, Brunet ME, Haddad RJ Jr. Fractured coracoid process in acromioclavicular dislocations. Report of four cases and review of the literature. Clin Orthop Relat Res, 1983, 175: 227-232. 